\title{
Psychological Concepts of Activity Theory in Child
}

\author{
Neuropsychology \\ Yulia Solovieva $^{1 *} \&$ Luis Quintanar ${ }^{1}$ \\ ${ }^{1}$ Faculty of Psychology, Autonomous University of Puebla, Mexico \\ *Yulia Solovieva, E-mail: yulia.solovieva@correo.buap.mx \\ Received: March 22, 2017 \\ Accepted: March 31, 2017 \\ Online Published: April 8, 2017 \\ doi:10.22158/jecs.v1n1p25 \\ URL: http://dx.doi.org/10.22158/jecs.v1n1p25
}

\begin{abstract}
Neuropsychology is the part of psychology, which studies the relation between psychological and brain level of organization of human activity. It is possible to identify specific mechanisms or components of psychological processes related to the functioning of special brain zones. Such a study can be based on different general psychological theories. From the point of view of activity theory approach these components can be understood as psycho-physiological structural and systemic mechanisms of actions and operations fulfilled by a subject in the context of one or another general activity. In other words, neuropsychological level of analyses could be understood as the elementary level of human activity. Neuropsychological analysis can be organized as assessment of actions and not of isolated functions. The present study shows how functional disorders of psychophysiological mechanisms can affect the fulfillment of the same actions of children with learning disabilities. The discussion stresses the importance of inclusion of the terms of activity theory to the practice in neuropsychology.
\end{abstract}

\section{Keywords}

theory of neuropsychology, activity theory, child neuropsychology, neuropsychological assessment, learning disabilities

\section{Introduction}

Neuropsychology is a particular branch of psychology, which studies the relation between psychological processes and brain level of organization of human activity. It is possible to say that neuropsychology studies possible relations between brain level and psychological level of activity. Through neuropsychological analysis, it is possible to identify brain specific mechanisms or components of psychological processes related to the functioning of special brain zones. Such a study can be based on different general psychological theories. Relation between level of brain mechanisms and psychological processes can be established by different manners.

Some authors try to precise the localization of different cognitive functions in specific brain zones 
(Goodglass \& Kaplan, 1972; Benson \& Ardila, 1998; Ardila, 2005; Rosselli \& Matute, 2012). The others claim that the brain with all structures works as a whole undividable unit, which is responsible for the subject's psychological abilities (Guimaraes, 2000). The first way of thinking is more common and more distributed in cognitive neuroscience today and is a kind of continuation of classic position of localization of psychological functions in brain structures. Such position proposes direct connection between brain structures and psychological processes. The new proposition of such way of thinking refers to the preference of localization of basic cognitive processes and more distributed brain participation for complex psychological processes (Bassett \& Gazzaniga, 2011; Gazzaniga \& Mangun, 2014).

The problem with this modern position is that there is no conceptual clarity for distinction between basic and complex cognitive processes. Anatomic terms are often used for description of basic cognitive process or their components. For example, the model proposed by Posner shows different systems of attention as different systems of brain regulation (Posner \& Peterson, 1990). In this interesting conception, attention might be understood as a complex process and it's components as basic processes. These basic process seams to have specific content, but they also might be understood as independent components of kinds of attention. It seams, according to such models, that the brain processes are given directly by brain and there is no place for complex process of psychological development or consolidation of functional systems starting from the early childhood. In other words, there is no conceptual difference between the level of brain mechanisms and complex psychological processes.

It is possible to notice that complex processes are not localized in these models, but are represented as distributed systems with diverse components. From the first glance, it is possible to find similarity between complex distributed models and A.R. Luria systemic and dynamic conception of localization of psychological processes in the brain. The difference is that Luria was not localizing psychological functions by themselves, but psychological functions were understood not as brain mechanisms localized in the brain. Psychological functions are understood as but complex cultural actions as writing, reading, speech comprehension, problems solving and so on. Each cultural action has it's "own cultural history" from the point of view of social development and of ontogenetic acquirement through the "history" of each particular child (Vigotsky, 1982; Luria, 1973). Such particular "history" always depends on particular features of social general culture and social situation of development in each concrete case (Vitogsky, 1984; Elkonin, 1980; Obukhova, 2006).

According to this position, we believe that is possible to speak about not only cultural historical psychology, but also of cultural historical neuropsychology. It is useful to use term of activity theory more precisely in order to stress systemic and dynamic relations between psychological processes and brain mechanisms. From the point of view of cultural historical neuropsychology it would be important to study specific cases of formation of functional brain systems as results of specific interaction between child and adult of group of children in different ages (Solovieva \& Quintanar, 2014a, 2016a). 
It is important to stress that this topic is extremely new and not yet perfectly understood by psychologists or neuropsychologists. The main point of cultural position in psychology and neuropsychology is that there is no possibility for maturation of functional brain systems out of consideration of activity, in which the child is included. In other words, nothing is "free of culture" on the level of human activity.

As for child neuropsychology, it is possible to notice that the circle of interests has become wider in recent twenty years. The children with and without learning disabilities and development problems are frequently included as subjects of neuropsychological assessment. First years of life and cases of genetic syndromes became also attractive for researchers. Groups with cognitive and behavioural problems without clear neurological signs are described in literature (Akhutina, 1997; Quintanar \& Solovieva, 2000).

It is interesting to observe that for some authors problems in school learning and development should necessarily have neurological base, which stricktly depend on the process of maturation of correspondent brain structures (Pineda \& Rosselli, 1997; Rosselli \& Matute, 2012). Such opinion shows a big constrast with commonly used typology of disorders accorsing to DSM-V, which doesn't provide any objective relation between behavioral external description of difficulties and the status of central nervous system.

According to Luria conception, neuropsychological analysis should be conducted on particular level called as the level of "neuropsychological factor" (Tsvetkova, 1998). This level should be differentiated from the level of cultural actions and from neurological neuroanathomic level of brain structures. The term neuropsychologicla factor refers to the result of work of brain structure (Mikadze \& Korsakova, 1994). We believe that it is useful to add that this is a result of functional participation of structures for completing specific roles inside different kinds of cultural actions (writing or reading of sentences or words, for example). These cultural actions might never be represented in the brain by one component or mechanisms, but by functional union of widely distributed mechanisms form diverse cortical and subcortical levels. One mechanism may participate in different actions and each action should include multiple mechanisms (Luria, 1947, 1969).

Cultural and historical origin of psychological actions is important position for neuropsychology. The child does not born with given actions of understanding, problems solution, reading and writing. Gradual psychological development and levels of acquisition of these actions continues to be an important object of multiple psychological investigations. Functional system with diverse cortical and subcortical components should become an object of research within developmental neuropsychology. The paths of ontogenetic development, possible changes in brain representation of the functions during infancy and never take into account, It seams to be that developmental psychology and neyropsychoogy have not yet met common terms in neuroscience.

The task of neuropsychologist is to determine precise functional stage (preservation or level of development) of each mechanism within specific functional system. Functional system is the level of 
brain representation of cultural action. From this point of view, cultural action would be represented in central nervous system as complex functional system; such system would include different (never only one) "neuropsychological factors" or functional mechanisms.

Vigotsky (1982) has defined systemic character of superior psychological functions; the difficulty of his conception consisted in the absence of new level for psychological analysis instead of the term "function". According to continuation of cultural tradition in psychology (Leontiev, 1975, 1983), the terms "activity" and "action" seams to be much more appropriate for systemic analysis of cortical and subcortical mechanisms in neuropsychology.

The concept of activity in psychology should not be understood as equal to the concept of "function". The term function has too broad meaning and might be applied to all levels of consideration: anatomic, physiological, neurological, genetic and so on. The concepts of activity and of action belong to cultural level of a subject and include motive, goal, orientation and result (Galperin, 1998; Leontiev, 2000; Talizina, 1984, 2009). Activity and action might only be formed as result of cultural social interaction between subjects (adult and child) and of learning process; these process are not given "as natural process". There is no sense for separation of "natural development" and "learning process", because all cultural actions are the result of learning process and are not given "by nature".

An important position for neuropsychology is that functional systems of brain cortical and subcortical mechanisms do not appear either "naturally", but only in actions and activities, where child is involved by adults during ontogenetic development.

Not only cultural actions, but also functional systems are the result and consequence of interaction, learning and joint social life. It is clear that functional systems might be "historically" changes together with the changes of cultural actions. Writing, reading, drawing, typing and calculation are only some of examples of cultural actions, which have suffered essential changes through history of mankind and are changing nowadays. Cultural differences of writing and reading are studies by different branches of sciences, but cognitive neuroscience speak of their precise fixed localization and dependence of genetic processes. On the contrary, in neuropsychological studies it was shown that brain representation of same abilities and actions, for examples, actions of visual perception, is different in adults and children (Simmernitskaya, 1985; Akhutina, 2001; Stiles et al., 1993). Our recent studies of children with attention deficit disorder have shown that brain mechanisms of this syndrome differ from age to age and that there are qualitative differences in troubles shown by pre-scholars and children of primary school and pre-adolescents (Solovieva \& Quintanar, 2015a, 2015b; Solovieva et al., 2016).

An action is the essential process of activity, and its motive corresponde to the same of activity. For example, the action of solution of arithmetic problem is only one of the actions, which belong to the activity of learning at school. At preschool age, one of examples of actions might be drawing of an object or of a landscape (Solovieva \& Quintanar, 2012, 2016a).

One of the tasks of neuropsychology is to study activity and action from the point of view of brain cortical and subcortical mechanisms, which take place for their realization. The level of Published by SCHOLINK INC. 
psychophysiological and neuropsychological mechanisms of actions is the level, which permits to establish dialectic relation between psychological processess as cultuarally formed actions and the level of organism. The mechanisns might be studies at different levels, por examples, from the point of view of neurophysiology (Anokhin, 1980; Bernstein, 1990) and more recent attempts to follow their complex wscheme of the unity of action and brain mechanisms (Machinskaya, 2012).

From the point of view of activity theory approach, brain components might be understood as psycho-physiological structural and systemic mechanisms of conscious actions and subconscious operations fulfilled by a subject in the context of one or another general activity. In other words, neuropsychological level of analyses could be understood as the elementary level of human activity.

According to Luria (1973), none of psychological functions could be localized directly in the human brain. Such proposition is based on theoretical comprehension of psychological functions or psychological processes. Psychological functions represent complex acquisitions, which pass through gradual development on different stages during the child's life (Vigotsky, 1984; Elkonin, 1989). All psychological processes appear firstly as external shared and collective material actions between adult and child (Vigotsky, 1984). Cultural objects are an integrative part of these actions and we might understand them even better as extra brain processes. Only later, psychological processes might be represented as internal individual processes.

We might remember proposal of Galperin to understand developed attention as internal function of control (Galperin, 1998), but firstly attention was an external collective action of control. According to this conception of cultural development, brain mechanisms of external collective action and individual internal action could not be same. Such fact is never taken into account by cognitive approach in neuropsychology, which always represents same distribution of psychological functions in the brain. For example, the components or systems of attention are the same in different ages; executive functions are given in prefrontal orbital zones and son on. We claim that these components could not be the same, because the process of attention is not the same in different psychological ages.

Psychological function as attention, memory, thinking and so on can represent direct object of psychological study, but even psychological studies often do not consider ontogenetic and qualitative changes of these processes. Neuropsychology has to study relation between these processes and take into account developmental aspects, which do not happen in the majority of studies. Neuropsychology has to propose its own level of analyses by its own units different from psychological terms. In Luria's words, neuropsychology realizes assessment of specific factors or components of psychological processes, which can be related to the functioning of central nervous system.

This kind of factorial functional analyses is nowadays successfully applied into child neuropsychology for analyses of cases of children with learning disabilities and retardation in psychological development (Korsakova, Mikadze, \& Balashova, 1996; Santana, 1999; Akhutina, 1999, 2001; Akhutina \& Pilayeva, 2003; Quintanar \& Solovieva, 2000, 2007, 2008).

Neuropsychology might be integrated into conception of cultural development of psychological activity 
not only in words, but also in a proper way of consideration of consolidation of complex functional systems in different psychological ages. According to our opinion, it is impossible to work as a child neuropsychologist without acceptation of general psychological explicative system in which brain factors or components of actions would be inserted. In our opinion it could be useful to apply general psychological activity theory to qualitative neuropsychological approach especially for cases of assessment and correction of learning disabilities and developmental problems in children of different ages. Let us explain how activity theory concepts might be useful for neuropsychology.

\section{Activity Theory Concepts}

From the point of view of activity theory the subject or personality has to be represented as subject of his own activity. The unit of psychological study is action and not function. According to Talizina $(1984,2009)$, the action could be understood as an elemental level of human activity, which conserves all significant components, such as motive, objective, result and means of execution. Examples of actions are writing of sentences; drawing of a house, playing with a doll, reading a text. All mentioned actions have same psychological invariant structure, but different content and might be analysed as shared actions or as individual actions of a child in each concrete case.

Different psychological phenomenon might be described in terms of actions instead of the terms of functions. For example the possibility of remembering and reproduction of information, which is related to traditional function of memory actually depends on specific actions of subject. Such action can be action of semantic or significant organization, action of coping of words, drawing of scheme and so on. Such processes can be realized as conscious or as automatic. In the second case, as automatic processes, they are operations and not actions, according to Leontiev's conception (Leontiev, 2000).

It is useful to cite Galperin's proposal for psychological study of attention once again. The process of attention can be understood as action of internal control (Galperin, 1998) and only internal automatized control is attention, that is: attention is always control, but not each control is attention. The memory and attention are not simply biological functions with which the child comes to the world but complex actions.

How might we include neuropsychological analysis to these activity theory terms?

Neuropsychological analysis could be proposed as assessment of cultural actions of a child instead of classic analyses of isolated psychological functions. For example, it is possible to propose the assessment of learning activity instead of assessment of memory, attention, perception and so on. The neuropsychological analysis of learning difficulties can be based on activity theory approach. In this case it is necessary to identify the structure of learning activity, which includes: motive, object (material, perceptive, verbal or combined), objective, orientation base of action and the sequence of operations. Each component can be fulfilled only in the case of conservation or adequate development of different neuropsychological mechanisms.

The learning process can be represented as specific activity of a child which consists of variety of 
different actions such as writing of words, pronunciation of sounds, counting, problem solution, reading and analyses of texts and so on. Each action and operation is realizing with the help of variety of elementary components at brain level. Neuropsychological analyses can provide the means and instruments for identification of preserved and disturbed mechanisms. Such an assessment can be useful for understanding of the learning process and of children with learning disabilities.

We can also suppose that in these terms and following Galperin's ideas (Galperin, 1998) traditional psychological functions represent automatized internal actions of organization (memory), control (attention). These actions depend not only on biological base but also on development or stage of other components of action: motive, objective and means. No action can be fulfilled by only one of traditional psychological functions. The action includes different combinations of all functions according to the nature and grade of acquisition of the action.

The learning process can be represented as specific activity of a child which consists of variety of different actions such as writing of words, pronunciation of sounds, counting, problem solution, reading and analyses of texts and so on. The high grade of internalisation and acquisition of these actions convert them in subconscious automatic operations. This level of functioning of activity permits to achieve new high goals and senses of personality. In our opinion this has to be the real goal of teaching and could be new perspective for organization of learning process at school.

The structure of the action depends on its real goal and on the grade of acquisition of action. For example, each particular task refers to particular goal. The task can be: "Write the sentence" or "Write the first letter of each word" and so on. Operations or means of each action will different. Each learning action might be fulfilled by a subject on different moments of learning process.

Table 1 represents action of writing in situation of dictation of a new sentence at school. The conscious goal of the action is to obtain the right sentence. This action includes at least four operations, which are necessary means of this action but none is it's conscious goal. In other words the pupil is not conscious of these means of the action. The problem or difficulty with any of these operations affects the action as a whole.

Each action includes series of operations, which are the essential means of realizations of the action. As we have said the action is always conscious while the operation is no reflected in the consciousness of the pupil. Such relation is dynamic and changes from the beginning to the end of the process of child's education. The teacher has to know that conscious actions can convert into automatic operations correctly only in case of their adequate representation at the initial level of education. That is, all four aspects of the action of writing has to be reflected in consciousness of the pupil ate the initial stage of learning process in order to pass to internal level at the end of this process.

What might neuropsychology introduce to such analyses of learning process? 
Table 1. Psychological Structure of Action

Action of writing by dictation

1) Phonological analyses of language.

Operations

2) Election of letters and theirs elements.

3) Organization of writing.

4) Verification.

It is clear that nor action neither operation can not be accomplished without participation of another elementary level which is level of central nervous system and brain level. Each action and operation is realizing with the help of variety of elementary components at brain level. Such components can be understood as psychophysiological mechanisms of actions and operations or as elemental level of human activity. Nowadays, it is convenient to call these mechanisms as neuropsychological mechanisms of actions. The analyses of the grade or luck of development of any of such components can explain the appearance of problems or difficulties which children so frequently manifest in their learning process. For example, we can analyse the structure of the action from neuropsychological point of view (Table 2).

Table 2. Neuropsychological Structure of Action. Action of Writing by Dictation

\begin{tabular}{ll}
\hline Operations & Neuropsychological mechanisms \\
\hline Phonological analyses of language & Phonemic discrimination \\
& Kinestesic analyses and synthesis \\
& Audio-verbal retention \\
Election of letters and theirs elements & Global perception \\
& Analytic perception \\
Organization of writing & Visual and spatial retention \\
& Spatial global perception \\
Verification & Motor kynetic organization \\
& Programming and control \\
\hline
\end{tabular}

According to the table it is possible to see that a large number of neuropsychological mechanisms participate in the action of writing and in it's four operations. As Luria has established no action can be fulfilled by only one neuropsychological mechanism. At the same time, one neuropsychological mechanism participates in different actions. Diverse variations of the possibilities of formation and development of these mechanisms with relation to aspects of cortical and subcortical maturation should be taken into account, especially in cases of youngest children (Lebedinsky et al., 1999). The 
mechanisms mentioned in the Table 2 might be included in diverse actions and operation in different ages according to systems of education and nursery (Quintanar \& Solovieva, 2002, 2008).

According to neuropsychology each mechanisms is related to the functioning of concrete zone or conjunction of zone at brain level. Luria called such mechanisms with particular term "factor" (Luria, 1948,1973 ). We have proposed to use the term brain cortical or subcortical mechanisms (Quintanar \& Solovieva, 2008; Solovieva \& Quintanar, 2014b, 2015a, 2016b). We can see this relation between neuropsychological factor and brain cortical and nearest subcortical zones in Table 3.

We would like to mention that Luria's conception might seem to be rather complex and difficult for understanding and usage in neuropsychological practice. At the same time, it is truly important to assure that the inclusion of this conception into general conception of historical and cultural development and activity theory research might help on the way of broad comprehension and acceptation of this model in modern neuropsychology.

Table 3. Relation between Brain Zones and Some Neuropsychological Mechanisms

\begin{tabular}{ll}
\hline Neuropsychological mechanisms & Brain zones \\
\hline Phonemic discrimination & Temporal of both hemispheres \\
Kinestesic analysis and synthesis & Parietal of both hemispheres with nearest \\
& subcortical levels \\
Audio-verbal retention & Temporal inferior \\
Global perception & Right posterior hemisphere \\
Analytic perception & Left posterior hemisphere \\
Visual and spatial retention & Occipital of both hemispheres \\
Motor kynetic organization & Frontal posterior and subcortical basal ganglia \\
Programming and control & Broad frontal lobes and nearest subcortical \\
& structures \\
General activation & Profound subcortical structures/brainstorm
\end{tabular}

Why activity theory is important for neuropsychology?

The neuropsychological analysis of learning difficulties could be based on activity theory.

We think that analyses of neuropsychological mechanisms without including them into general model of human activity make little sense. In other words, all neuropsychological mechanisms participate not only as biological natural functions, but only as elementary components of actions and operations. These actions and operation might be developed and formed only as a result of cultural interaction between adult and child (Vigotsky, 1984; Leontiev, 2000; Tomasello, 2013). It is clear that cultural activity, reading or drawing, cannot be accomplished without participation of its material base (brain structures). But according to historic-cultural psychological conception development of 
neuropsychological mechanisms depends on their inclusion in concrete activity. Such activity is always cultural by nature, depends on the history of humankind and is specific for different historical periods and social situations (Leontiev, 1975, 1983, 2000; Tomasello, 2013; Solovieva \& Quintanar, 2010).

The example can be neuropsychological mechanism of spatial complex analyses and synthesis. This mechanism is related to the functioning of temporal parietal-occipital zones of both hemispheres. This functioning can be achieved only by inclusion of the subject in the activity of complex spatial orientation: drawing, reading, writing and so on. The luck of such activity can conduce to the luck of development of these mechanisms and convert in the reason of learning disabilities.

In this presentation we would like to show examples of neuropsychological analyses in cases of learning difficulties with the help of activity theory model. For this objective we have chosen one Mexican girl with learning disabilities.

As an example of neuropsychological analyses of a case of learning disabilities we present case of the girl of 8 years old with serious learning disabilities, who attended the second year of private school in the city of Merida (State of Yucatan in East South of Mexico; Yucatan Peninsula). The girl presents severe difficulties in matters of mathematics, reading and writing at school and receives extremely low school marks. Pedagogical, traditional psychological and neurological evaluation has detected attention deficit disorder.

Our own neuropsychological assessment based on Luria's theory of functional and dynamic representation of brain mechanisms has detected particular difficulty with the mechanisms of motor kinetic sequential organization of actions and movements. The assessment includes special tasks for evaluation of these mechanisms. One of them is a copy of a graphic sequence (Figures 1-2).

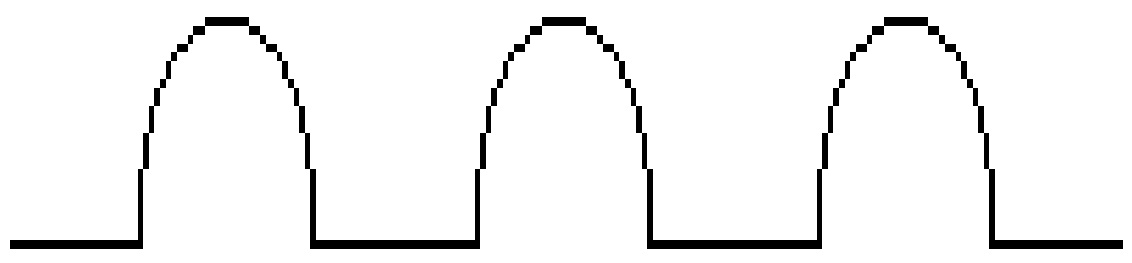

Figure 1. Model of the Task for Copy

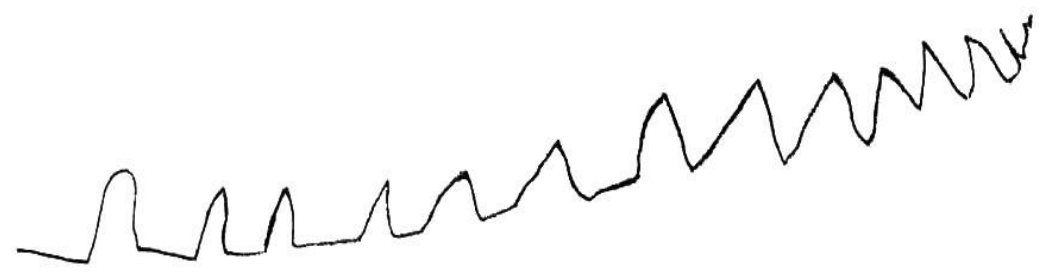

Figure 2. Execution by the Patient 
We can observe total impossibility of execution of this task. The girl commits mistakes, which are called perseverations, simplification of the presented program and losing of the model. The same type of difficulties was detected in other motor tasks such as serial coordination of hands and of fingers. The execution is characterized by stereotyped movements, simplification of given model and constant perseverations. Same of kind of difficulties might be seen not only in one isolated task, but in all kinds of tasks of neuropsychological assessment and of school tasks in every day life. According to all these facts we can notice poor functional development of evaluated mechanism. This mechanism is motor sequential organization of movements and actions.

Why the learning process is so affected in this girl?

The same kinds of difficulties are found during the execution of simple task "write down the date and your name" were inert repetition of parts of the words is observed (Figure 3).

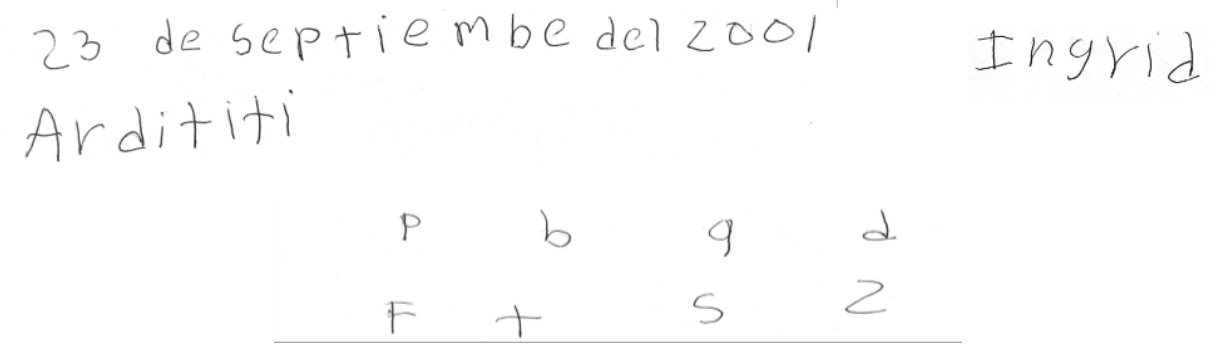

Figure 3. Date and Name

As for the task of finding of three words which stars with the letter "b", letter "s", letter "a", the girl shows many mistakes which are closely determined by detected mechanisms of sequential kinetic organization (Figure 4). A lot of repetitions, stagnations, perseverations are observed. Parts of words and complete previous words are introduced into the creative task of proposing of independent examples of words.

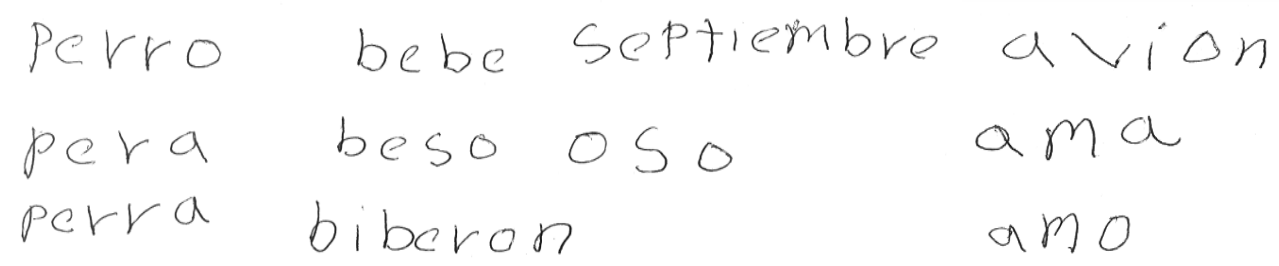

Figure 4. Independent Words

It is important to mention that the girl has high motivation for realization of the proposed tasks but she is unable to correct her mistakes. 


\section{Discussion}

In our opinion traditional diagnostic cannot explain the difficulties nor help for election of adequate methods of correction. The term attention deficit refers to consideration of only one psychological function of attention without its concrete real relation to other functions, neither to its proper neuropsychological mechanisms nor to school actions and operations.

Neuropsychological analyses presented above fulfilled form the perspective of general activity theory can bring much more information and explain real neuropsychological mechanisms in cases of learning disabilities (Korsakova, Mikadze, \& Balashova, 1997; Tsvetkova, 1998; Semago et al., 1999; Akhutina, 2002; Luria \& Tsvetkova, 1997; Solovieva \& Quintanar, 2007).

This analyses, as a result of neuropsychological qualitative assessment, includes the following:

1) Detailed description of essential symptoms of perseveration, repetitions, simplifications of models.

2) Identification of central neuropsychological mechanisms of motor sequential motor organization.

3) Discovery of actions and operations with are affected by insufficient development of this mechanism.

The relation between these three steps of neuropsychological assessment together with the synthesis of the content of each step is represented in Table 4.

According to the Table 4, we can see non-traditional understanding of the syndrome of difficulties (Solovieva \& Quintanar, 2007). We can identify level of symptoms, which are presented in all actions of the girl. We can provide synthesis of these symptoms and identify the central mechanisms of the clinic picture. And later one, we might find all kinds of school and intellectual actions, which are suffering on the basis of the central reason. The term "attention deficit disorder" would give us no coherent explanation of the case. At the same time, it is not correct to suppose that each cases of attention deficit disorder have always the same constellation of symptoms, central mechanisms and actions. Previous experience and research have shown that different neuropsychological variant of syndromes are possible, when children of different ages receive diagnosis of "attention deficit disorder" (Machinskaya et al., 2014; Glozman \& Shevchenko, 2014; Solovieva \& Quintanar, 2014a, 2015a). Each case has to be assessed and examined in a detailed clinic matter.

Table 4. Steps of Neuropsychological Assessment Based on Activity Theory Concepts

\begin{tabular}{lll}
\hline Identification of symptoms & Central mechanism & Actions \\
\hline Perseverations and constant & Motor sequential organization & All actions, which include motor \\
repetition of previous steps as & as a result of participation of & organization in sequences: hand \\
complex motor difficulties in all & cortical and/or subcortical motor & writing, oral speech production \\
tasks, which are expressed as & structures. & of phrases and sentences; \\
systems and steps of & & drawing, coping, writing by \\
movements. & & dictation; constructions; \\
\hline
\end{tabular}


grammar syntactic organization

of oral and writing self

production, understanding of

meaning of texts and so on.

It is important to take into account that same particular functional deficit of motor sequential organization of movements and actions, related to participation of frontal posterior cortical and subcortical structures, produce systemic complex effect on school success and intellectual development of the girl. Her difficulties might be called as attention deficit disorder or low intellectual coefficient, but such terms explain nothing of her own neuropsychological and psychological development. This important aspect of neuropsychological assessment might be carried out only on the basis of the concepts of systemic activity theory.

In the studied case affected neuropsychological mechanism was motor sequential kinetic organization of movements and actions. This mechanism guarantees realization of fine motor sequences at all levels: motor movements in writing and speech, reading, codification and de-codification of grammar syntactic structures and so on. The poor development of this mechanism has a systemic effect for all school actions of the girl and explains her low level of school success and specific errors and difficulties in intellectual tasks.

At the same time we can notify good development of phonologic discrimination, which is one of mechanisms of phonemic and kinestesic analyses and synthesis. This fact is important and can serve as a base during elaboration of methods for correction. In this sense the program of corrections has to be directed not to exercises for strengthening of attention, but to gradual formation of motor sequences at all levels (Solovieva \& Quintanar, 2014b).

How would it be possible to help the child? Just give her medicine, as the majority of child neurologists and psychiatrists do in all countries of Latina America?

From one hand, it is possible to call it "attention deficit disorder" or with any other traditional term. In any case, such term would take into account only one function and not the entire sphere of the child's activity and would not offer profound understanding of the difficulties with central nervous system. In these cases, the specialists are used to provide medication and no specific recommendations accept modification of behaviour.

From the other hand, our way of assessment and understanding of difficulties offer new perspective for correction. Gradual training and work with motor sequential organization starting from the level of material actions in tasks of organization of situations in series of objects in joint actions and representations would be excellent recommendations for elaboration of the program for rehabilitation in this case (Solovieva \& Quintanar, 2008).

A proper proposal of cultural neuropsychology would be inclusion of the girl in specific activities guided by an expert adult, which should include in their content the mechanisms of sequential motor 
organization of movements and actions. The work would be slow, but sure. The positive effects of such kind of intervention in the cases of developmental disorders and learning disabilities were shown in different publications (Solovieva \& Quintanar, 2015b, 2016c).

The present study shows how functional disorders of neuropsychological mechanisms might have important effects on the fulfilment of the school actions of children with learning disabilities. We stress the importance of inclusion of the terms of activity theory to the practice in neuropsychology.

\section{Conclusions}

Our study shows the necessity and posibillity of combination of concepts of general psychology and neuropsychology. Modern neuropsychology is not an isolated branch of knowledge with no relation to fundamental conceptos of general psychology. At the same time, it is not only a mixture of diverse knowledge of "neuroceicnes" with no basis of general conception of human development. Particular concepts of cultural psychology conduct to particular understanding of the role of brian mechanisms in cultural activities. Child neuropsychology should take into account fundamental and classic works of developmental cultural psychology. The theory of gradual develpment starting from combined shared joint actions of adult and child is one of such conceptual offers from general psychology. Cultural qualitative neuropsychology is able to offer new original understanding of learning disabilities in a systemic functional basis.

\section{References}

Akhutina, T. V. (1997). Neuropsicología de las diferencias individuales de los niños como base para la utilización de los métodos neuropsicológicos en la escuela. Escuela de la Salud, 4, 9-17.

Akhutina, T. V. (1999). Aproximación neuropsicológica hacia el diagnóstico de las dificultades en el aprendizaje. In E. D. Xomskaya (Ed.), Chrestomatía sobre neuropsicología (pp. 453-455). Moscú, Sociedad Psicológica Rusa.

Akhutina, T. V. (2001). Aproximación neuropsicológica hacia el diagnóstico y corrección de las dificutlades en el aprendizaje de la escritura. In M. G. Jrakovskaya (Ed.), Aproximaciones contemporáneas hacia el diagnóstico y la corrección de los trastornos del lenguaje (pp. 195-213). San Petersburgo: Universidad de San Petersburgo.

Akhutina, T. V. (2002). Diagnóstico y corrección de la escritura. Revista Española de neuropsicología, $4(2-3), 236-261$.

Akhutina, T. V., \& Pilayeva, N. M. (2003). Diagnóstico y desarrollo de las funciones visuo-verbales. Moscú: Academia.

Akhutina, T. V., \& Zolotariova, E. V. (2001). Acerca de la disgrafía visuo-espacial. In Y. Solovieva \& L. Quintanar (Eds.), Métodos de intervención en la neuropsicología infantil (pp. 39-46). México, Universidad Autónoma de Puebla.

Anokhin, P. K. (1980). Problemas claves de la teoría del sistema funcional. Moscú: Ciencia. 
Ardila, A. (2005). Las afasias. Miami: Florida International University.

Bassett, D. S., \& Gazzaniga, M. S. (2011). Understanding complexity in the human brain. Trends in Cognitive Neurosciences, 15(5), 200-209. https://doi.org/10.1016/j.tics.2011.03.006

Benson, D. F., \& Ardila, A. (1996). Aphasia: A clinical perspective. New York: Oxford University Press.

Bernstein, N. A. (1990). Fisiología de los movimientos y de la actividad. Moscú: Ciencia.

Elkonin, D. B. (1980). Psicología del juego. Madrid: Pablo del Río.

Elkonin, D. B. (1989). Obras psicológicas escogidas. Moscú: Pedagogía.

Galperin, P. Y. (1998). Actividad psicológica como ciencia objetiva. Moscú: Academia de Ciencias Pedagógicas y Sociales.

Gazzaniga, M. S., \& Mangun, G. R. (2014). The cognitive neurosciences. Cambridge: MIT Press.

Glozman, J., \& Shevchenko. (2014). Executive functions in children with ADHD. Psychology \& Neuroscience, 7(4), 453-460. https://doi.org/10.3922/j.psns.2014.4.04

Goodglass, H., \& Kaplan, E. (1972). The assessment of aphasia and related disorders. Philadelphia: Lea and Febiger.

Korsakova, N. K., Mikadze, Y. V., \& Balashova, E. Y. (1996). Niños con problemas en parendizaje: Diagnóstico neuropsicológico de las dificultades de aprendizaje en escolares menores. Moscú: Agencia Pedagógica Rusa.

Lebedinsky, V. V., Markovskaya, I. F., Lebedinskaya, K. S., Fishman, M. N., \& Trush, V. D. (1999). El análisis clínico neuropsicológico y neurofisiológico de las animalías del desarrollo psicológico de niños con disfunción cerebral mínima. In A.R. Luria y la psicología contemporánea (pp. 62-68). Moscú, Universidad estatal de Moscú.

Leontiev, A. N. (1975). Actividad, conciencia, personalidad. Moscú: Universidad Estatal de Moscú.

Leontiev, A. N. (1983). Obras psicológicas escogidas. Moscú: Universidad Estatal de Moscú.

Leontiev, A. N. (2000). Conferencias sobre psicología general. Moscú: Sentido.

Luria, A. R. (1947). Afasia traumática. Moscú: Academia de las Ciencias Médicas.

Luria, A. R. (1948). Rehabilitación después de heridas de guerra. Moscú: Academia de las Ciencias Médicas.

Luria, A. R. (1969). Las funciones corticales superiores del hombre. Moscú: Universidad Estatal de Moscú.

Luria, A. R. (1973). Problemas de neuropsicología. Moscú: Universidad Estatal de Moscú.

Luria, A. R., \& Tsvetkova, L. S. (1997). Neuropsicología y problemas en aprendizaje en la escuela normal. Moscú, Academia de Ciencias Pedagógicas y Sociales.

Machinskaya, R. (2012). Why does Psychologist need "Social Brain"? Cultural-historical Psychology, 2012(4), 103-108.

Machinskaya, R., Semenova, O., Absatova, K., \& Sugrobova, G. (2014). Neuropsychological factors assotiated with cognitive déficits in children with ADDH: EEG and neuropsychological analysis. 
Psychology \& Neuroscience, 7(4), 473-561. https://doi.org/10.3922/j.psns.2014.4.05

Mikadze, Y. V., \& Korsakova, N. K. (1994). Diagnóstico y corrección neuropsicológica de los escolares menores. Moscú: IntelTex.

Obukhova, L. F. (2006). Psicología de las edades psicológicas. Moscú: Educación Superior.

Pineda, D., \& Rosselli, M. (1997). Hiperactividad y Trastornos Atencionales. In M. Rosselli, A. Ardila, D. Pineda, \& F. Lopera (Eds.), Neuropsicología infantil. Avances en investigación, teoría y práctica (pp. 253-278). Medellín: Prensa Creativa.

Posner, M. I., \& Peterson, S. E. (1990). The attention system of the human brain. Annual Review of Neuroscience, 13, 25-42. https://doi.org/10.1146/annurev.ne.13.030190.000325

Quintanar, L., \& Solovieva, Y. (2000). La discapacidad desde la perspectiva neuropsicológica. In M. A. Cubillo, J. Guevara, \& A. Pedroza (Eds.), Discapacidad humana, presente y futuro. El reto de la rehabilitación en México (pp. 51-63). Tlaxcala: Universidad del Valle de Tlaxcala.

Quintanar, L., \& Solovieva, Y. (2002). Análisis neuropsicológico de las alteraciones del lenguaje. Revista de Psicología General y Aplicada, 55(1), 67-87.

Quintanar, L., \& Solovieva, Y. (2008). Aproximación histórico-cultural: Fundamentos teórico-metodológicos. In J. Eslava, L. Mejía, L. Quintanar, \& Y. Solovieva (Eds.), Los trastornos de aprendizaje: Perspectivas neuropsicologías (pp. 145-182). Bogotá, Magisterio.

Rosselli, M., \& Matute, E. (2012). Desarrollo neuropsicológico y maduración cerebral. In E. Matute (Ed.), Tendencias actuales de las Neurociencias cognitivas (pp. 87-100). México: Manual Moderno.

Santana, R. (1999). Aspectos neuropsicológicos de aprendizaje escolar. San Juan, Puerto Rico: Innovaciones Psicoeducativas.

Semago, M. M., Akhutina, T. V., Semago, N. Y., Svetlova, N. A., \& Bereslavskaya, M. I. (1999). Evaluación psicólogo-médica del niño. Moscú: ARKTI.

Simmernitskaya, E. G. (1985). El cerebro humano y los procesos psiquicos en la ontogenia. Moscú: Universidad Estatal de Moscú.

Solovieva, Y., \& Quintanar, L. (2007). Principios y estrategias para la evaluación neuropsicológica infantil. In E. A. Escotto Córdova, M. Pérez Mendoza, \& N. A. Sánchez Cortés (Eds.), Lingüística, neuropsicología y neurociencias ante los trastornos del desarrollo infantile (pp. 87-101). México, UNAM.

Solovieva, Y., \& Quintanar, L. (2010). Antología del desarrollo psicológico del niño preescolar. México: Trillas.

Solovieva, Y., \& Quintanar, L. (2012). Formation of drawing activity in Mexican preschool children. Psychology Research, 2(8), 479-489.

Solovieva, Y., \& Quintanar, L. (2014a). Enseñanza de la lectura. Método práctico para la formación lectora. México: Trillas.

Solovieva, Y., \& Quintanar, L. (2014b). Syndromic analysis of ADDH at preschool age according to 
A.R. Luria concept. Psychology and Neuroscience, 7(4), 443-452. https://doi.org/10.3922/j.psns.2014.4.03

Solovieva, Y., \& Quintanar, L. (2014c). Principios y objetivos para la corrección y el desarrollo en la neuropsicología infantil. In H. Patiño, \& A. López (Eds.), Prevención y evaluación en Psicología (pp. 61-74). Manual Moderno.

Solovieva, Y., \& Quintanar, L. (2015a). Qualitative síndrome analysis by neuropsychological assessment in prescholers with attention déficit disorder with hyperactivity. Psychology in Russia: State of the Art, 8(3), 1-12.

Solovieva, Y., \& Quintanar, L. (2015b). Games as a Method of Correction in Prescool Mexican Children with ADDH. British Journal of Education, Society and Behavioural Science, 11(3), 1-14.

Solovieva, Y., \& Quintanar, L. (2016a). El dibujo como actividad formativa en la edad preescolar. México: Trillas.

Solovieva, Y., \& Quintanar, L. (2016b). Análisis sindrómico en casos de problemas de desarrollo y aprendizaje: Siguiendo a A.R. Luria. In D. F. Da Silva Marques, J. H. Ávila-Toscano, H. Góis, J. Leonel, N. Ferreira, Y. Solovieva, \& L. Quintanar (Eds.), Neuroscience to Neuropsychology: The study of the human brain (Vol. I, pp. 387-414). Barranquilla, Colombia: Corporación Universitaria Reformada.

Solovieva, Y., \& Quintanar, L. (2016c). Educación neuropsicológica infantil. México:Trillas.

Solovieva, Y., Pelayo, H., Méndez, I., Machinskaya, R., \& Morán, G. (2016). Correlación de análisis neuropsicológico y electroencefalográfico en escolares con diagnóstico de TDA. Neurobiología, $7(15), 1-15$.

Stiles, J., Reilly, J., Paul, B., \& Moses, P. (2005). Cognitive development following early brain injury: Evidence for neural adaptation. Trends in Neuroscience, 9(3), 136-143. https://doi.org/10.1016/j.tics.2005.01.002

Talizina, N. F. (1984). Dirección del proceso de asimilación de conocimientos. Moscú: Universidad Estatal de Moscú.

Talizina, N. F. (2009). La teoría de la actividad aplicada a la enseñanza. México: Universidad Autónoma de Puebla.

Tomasello, M. (2013). Los orígenes de la comunicación humana. Madrid: Katz Editores.

Tsvetkova, L. S. (1998). Metódica para el diagnóstico neuropsicológico infantil. Moscú: Agencia Pedagógica Rusa.

Vigotsky, L. S. (1982). Obras psicológicas escogidas. Tomo 1. Moscú: Pedagogía. Vigotsky, L. S. (1984). Obras psicológicas escogidas. Tomo 6. Moscú: Pedagogía.

Xomskaya, E. D. (1999). Problema de los factores en la neuropsicología. In E. D. Xomskaya (Ed.), Chrestomatía sobre neuropsicología (pp. 90-94). Moscú: Sociedad Psicológica Rusa. 